\begin{tabular}{|c|c|c|}
\hline \multirow{3}{*}{ BENTHAM OPEN } & $\begin{array}{c}\text { The Open Construction and Building } \\
\text { Technology Journal }\end{array}$ & $\begin{array}{l}\text { The Open } \\
\text { Construction \& Building } \\
\text { Trechnology lournal }\end{array}$ \\
\hline & Content list available at: www.benthamopen.com/ТОВСТЈ/ & \\
\hline & DOI: $10.2174 / 1874836801610010431$ & \\
\hline
\end{tabular}

RESEARCH ARTICLE

\title{
Experimental and Numerical Analysis of Cement Based Composite Materials with Styrofoam Inclusions
}

\author{
Kurt Strecker*, Carlos Augusto da Silva and Sérgio Luiz Moni Ribeiro Filho \\ Federal University of São João Del-Rei, Praça Frei Orlando, 170, São João Del-Rei, MG, Brazil
}

Received: April 22, 2015

Revised: June 11, 2015

Accepted: November 5, 2015

\begin{abstract}
In civil engineering an increasing demand for lightweight concretes exists, because a lower density results in significant benefits for structural elements. Polystyrene foams may be used in the fabrication of lightweight concretes with a large density range. In this work, the influence of fine grained sand $(<1 \mathrm{~mm})$ additions of 5, 10 and $20 \%$ on the properties of a composite consisted of cement with styrofoam inclusions of 20,40 and $60 \%$ has been studied. Finite element analysis (FEA), using Abaqus software package, was carried out to predict numerically the effect of particle size and polystyrene fraction on the compressive strength of the composite materials. The composites were characterized by their density, porosity and compressive strength after 28 days. The density of the composites varied between 1250 and $1600 \mathrm{~kg} / \mathrm{m}^{3}$ with a strength of 18 and $9 \mathrm{MPa}$ for 20 and $60 \%$ of Styrofoam inclusions, respectively. The increase of the fraction of sand from 5 to $20 \%$ promoted the increase in bulk density and modulus of the composites. The effect of the addition of sand on the porosity and mechanical strength exhibited variation indicating the packing factor of the particles as the main responsible for this behavior. Based on the finite element analysis the amount of the stress in the composite increases with the increasing particle diameter. The composites investigated exhibited a uniform distribution of the polystyrene spheres, allowing their use for non-structural purposes.
\end{abstract}

Keywords: Composite particulate, Cement, Finite element analysis, Styrofoam.

\section{INTRODUCTION}

In civil engineering an increasing demand exists for lightweight concretes with elevated specific strength, i.e. a high strength to density ratio, resulting in significant benefits for structural elements.

Low specific weight materials can be used as aggregate in this type of concrete, being classified by its origin into natural (pumice, diatomaceous earth, volcanic clinkers, etc.) and artificial (perlite, expanded shale, clay, slate, sintered PFA etc.) aggregates. Expanded polystyrene, EPS, is a synthetic aggregate of ultralow density below $300 \mathrm{~kg} / \mathrm{m}^{3}$ [1, 2], also known under its commercial trade mark as Styrofoam. Due to its low density EPS can be used in the fabrication of lightweight concretes for applications such as coating panels, wall curtains, and floor and concrete blocks [3, 4]. This type of material can also be used for specific applications such as base floor, railway beds, as construction material for floating offshore structures or barriers and as a material that absorbs energy in the protection of underground military installations [5 - 9]. The incorporation of EPS beads into cement at different amounts results in an ample range of density of the composite materials.

Styrofoam aggregates can replace partially or completely the fine aggregates commonly used in concrete or the sand in the case of mortars. Many studies were conducted with expanded polystyrene incorporated in masses with ordinary Portland cement as binder.

In some works the use of epoxy resins dissolved in water and dispersions of polyvinyl propionate [10] or a chemical treatment of the expanded polystyrene beads [11] was reported in order to compensate the hydrophobic characteristics

\footnotetext{
* Address correspondence to this author at the Federal University of São João Del-Rei, Praça Frei Orlando, 170, São João Del-Rei, MG, Brazil; Tel/Fax: +55 (32) 33792595; E-mail: strecker@utsi.edu.br
} 
of the beads. Other researchers reported that the polystyrene spheres tend to fluctuate, which may result in an inhomogeneous mixture due to segregation, making the use of additives required [6, 7].

Babu and Babu [12] and Zhang and Gjorv [13] studied the production and the mechanical properties of concrete with incorporated polystyrene spheres. To avoid segregation of the polystyrene beads they added fine sand of particle size below $2.3 \mathrm{~mm}$. They obtained concretes with density varying from 1500 to $2000 \mathrm{~kg} / \mathrm{m}^{3}$ and strength of 10 to 20 $\mathrm{MPa}$, for polystyrene additions in the range of 20 to $40 \%$ by volume. Tang et al. [14] added expanded polystyrene in the range of 20 to $60 \%$ by volume, reporting that density, mechanical strength and modulus of elasticity decrease depending on the amount of polystyrene in the mixture. Furthermore, they report a strong dependency of the long term properties on the volume fraction of expanded polystyrene and curing time. In another work, Babu and Babu [15] investigated the addition of up to $95 \%$ of expanded polystyrene in concrete mixtures and obtained materials with a density as low as 550 $\mathrm{kg} / \mathrm{m}^{3}$. They also reported that due to the polystyrene additions water absorption is less than for normal concrete and that chemical resistance is improved.

In this investigation the influence of the amount of sand of 5, 10 and $20 \%$ and the amount of polystyrene of 20,40 and $60 \%$ on the properties of a composite based on a Portland cement matrix has been studied.

It has been found that the amount of sand, in the proportions used in this work, exercises only a small influence on the variables studied, while the amount of expanded polystyrene beads strongly influences the properties of the composite material. Furthermore, finite element analysis confirmed these findings by the analysis of stresses and indicates that larger Styrofoam particles result in higher stresses than smaller particles.

\section{MATERIALS AND METHODS}

In this work, Portland cement (CP-V) supplied by Holcim Corporation of Brazil and sand of particle size smaller than $0.177 \mathrm{~mm}$ (mesh 80 ) has been used as matrix material, besides polystyrene spheres with a diameter smaller than 5 $\mathrm{mm}$ as dispersed, secondary phase.

The variables investigated in this experiment were: volumetric density, bulk density, apparent porosity, water absorption, compressive strength and modulus of elasticity. As relevant factors of investigation in this work the mass fraction of sand, $(5 \%, 10 \%$ and $20 \%)$ and the volume fraction of polystyrene $(20 \%, 40 \%$ and $60 \%)$ were chosen. Factors held constant in this work were: curing time (28 days), water/cement ratio (0.4), matrix type (Portland cement) and manufacture at room temperature $\left(25^{\circ} \mathrm{C}\right)$. Table 1 shows the levels and investigated experimental factors, establishing a factorial design 32, providing 9 different experimental conditions.

Table 1. Experimental conditions, complete factorial design $\left(3^{2}\right)$.

\begin{tabular}{|c|c|c|}
\hline Experimental conditions & Sand (wt-\%) & Polystyrene (vol.-\%) \\
\hline C1 & 5 & 20 \\
C2 & 5 & 60 \\
C3 & 5 & 20 \\
C4 & 10 & 40 \\
C5 6 & 10 & 60 \\
C7 & 10 & 40 \\
C8 & 20 & 60 \\
C9 & 20 & 20 \\
\hline
\end{tabular}

The random method was adopted for the preparation of the specimens. This allowed an arbitrary ordering of experimental conditions, preventing that effects of uncontrollable factors would affect the response of variables [10].

For the manufacture of the composites cylindrical plastic molds of $47.5 \mathrm{~mm}$ diameter and $95.0 \mathrm{~mm}$ height were used, i.e. height equals two times the diameter. After mixing the material was poured into the molds and cured for 28 days. Prior to the compression tests the samples were cut to ensure parallelism. Six samples were prepared for each experimental condition. Considering the adoption of two replicas and nine experimental conditions, 108 specimens at total were prepared. A replica is the repetition of the experimental condition, providing an estimated experimental error of an individual response. The extent of this error is important in deciding whether or not there are significant effects that might be associated to the action of factors. The statistical software Minitab version 14 was used for the processing of the data using the tool Design of Experiment (DOE) and Analysis of Variance (ANOVA).

The volumetric density, bulk density, apparent porosity and water absorption were determined using the following equations (I) - (IV): 


$$
\begin{aligned}
& B=\frac{M_{1}}{V} \\
& T=\frac{M_{1}}{M_{1}-M_{3}} \\
& P=\frac{M_{2}-M_{1}}{M_{2}-M_{3}} \times 100 \\
& E=\frac{M_{2}-M_{1}}{M_{1}} \times 100
\end{aligned}
$$

B is the volumetric density $\left(\mathrm{g} / \mathrm{cm}^{3}\right)$, M1 the mass of the dry composite $(\mathrm{g}), \mathrm{T}$ the bulk density, $\mathrm{M} 2$ the mass saturated with water $(\mathrm{g}), \mathrm{P}$ the apparent porosity, M3 the mass of the immersed specimen $(\mathrm{g})$, E the water absorption $(\%)$, and $\mathrm{V}$ the specimen volume $\left(\mathrm{cm}^{3}\right)$.

The apparent porosity and bulk density tests followed the recommendations of the British Standard BS EN ISO 10545-3 (1995) [16]. To investigate the compressive strength values, a universal testing machine was used, and compression tests were being conducted under a constant crosshead speed of $5 \mathrm{~mm} / \mathrm{min}$.

The elastic modulus was determined by the resonance frequency, using the Erudite MKIV Resonant Frequency Test System. This study was conducted in accordance with ASTM-C215-08 [17] for longitudinal frequency. The dynamic modulus of elasticity was calculated by equation $(\mathrm{V})$ :

$$
E=5.093 \times\left(\frac{L}{d^{2}}\right) \times M \times\left(n^{\prime}\right)^{2}
$$

In this equation, $\mathrm{E}$ represents the dynamic modulus of elasticity, $\mathrm{L}$ the length of the specimen, $\mathrm{d}$ the diameter, $\mathrm{M}$ the specimens mass and $\mathrm{n}^{\prime}$ its fundamental longitudinal frequency.

\subsection{Modeling Procedure}

Finite element analysis (FEA) was carried out to predict numerically the effect of particle size and polystyrene fraction on the compressive strength of the composite materials. Simulations of uniaxial compressive tests were performed on 3.5 (model A and B) and $5 \mathrm{~mm}$ (model C and D) hole models with different volume fractions, see Fig. (1). The 3D-idealized cement composite was modeled by replacing Styrofoam particles of almost zero strength by holes of the same sizes arranged randomly. The diameter and height of the studied composite were $47.5 \mathrm{~mm}$ and 95 $\mathrm{mm}$, respectively. Finite element meshes were obtained using Abaqus software package. An 8-node linear brick, reduced integration and hourglass control elements were used in all computations.

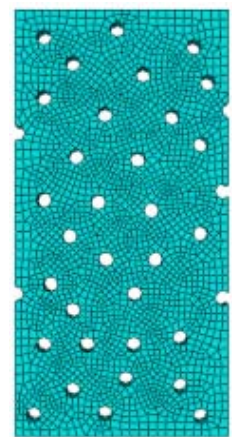

(a)

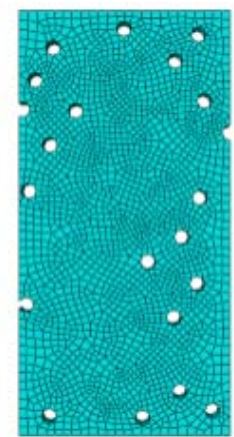

(b)

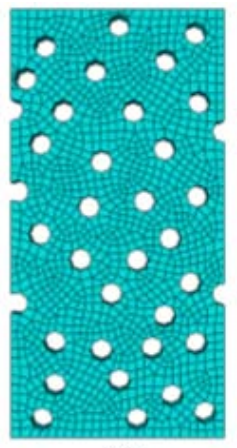

(c)

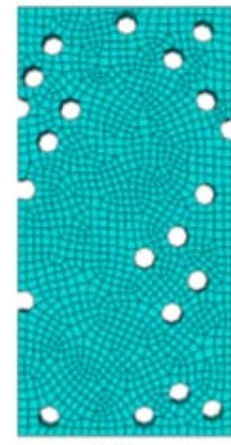

(d)

Fig. (1). Model A (a), Model B (b), Model C (c), and Model D (d).

The cylindrical specimen has been considered as deformable and isotropic solid (Fig. 2), according to the mechanical behaviour reported by Babu and Babu [12]. The plate has been considered as a discrete rigid solid that does not suffer deformations. Surface to surface contact was defined as the interface region plate/cylinder with a friction coefficient of 0.1 . The 3D model was based on the explicit integration. 

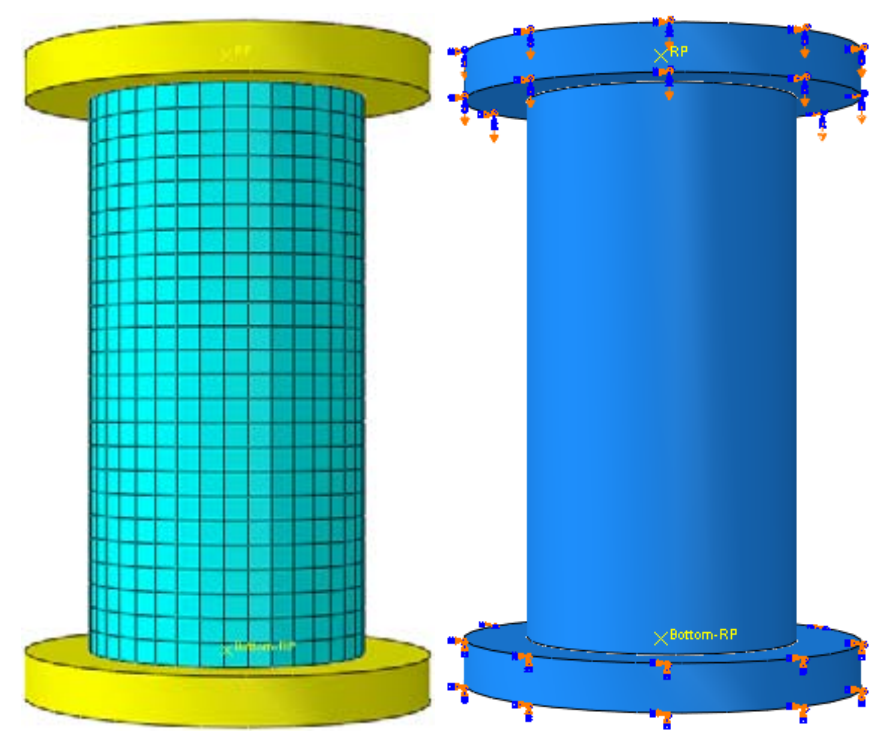

Fig. (2). Boundary conditions for uniaxial compression tests.

\section{RESULTS}

Fig. (3) shows a photo of a specimen containing $40 \%$ of polystyrene spheres as aggregate. The formation of internal pores can be attributed to the manufacturing process. Fig. (4) shows a longitudinal cross-sectional image of the investigated specimens (C1-C9) where a homogeneous distribution of Styrofoam particles can be verified.

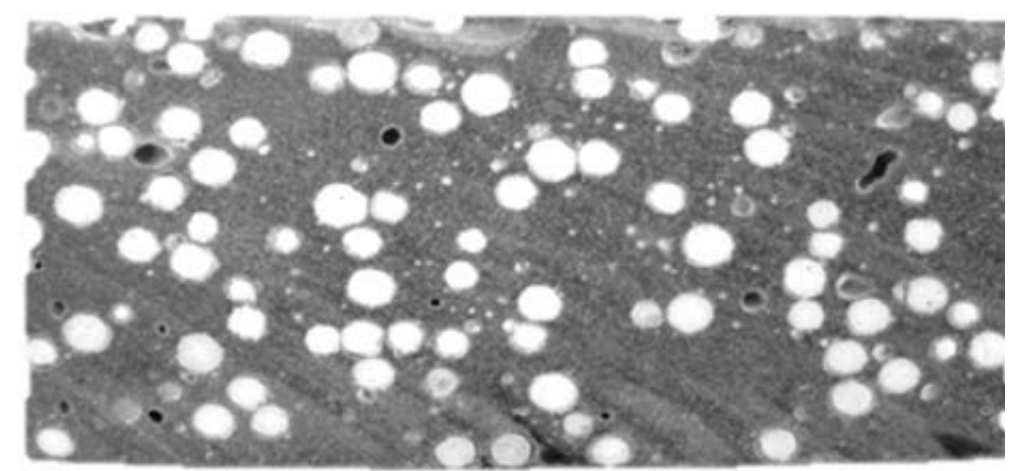

Fig. (3). Longitudinal section of a specimen containing 20\% of Styrofoam and 20\% sand (composition C7) after 28 days of curing.

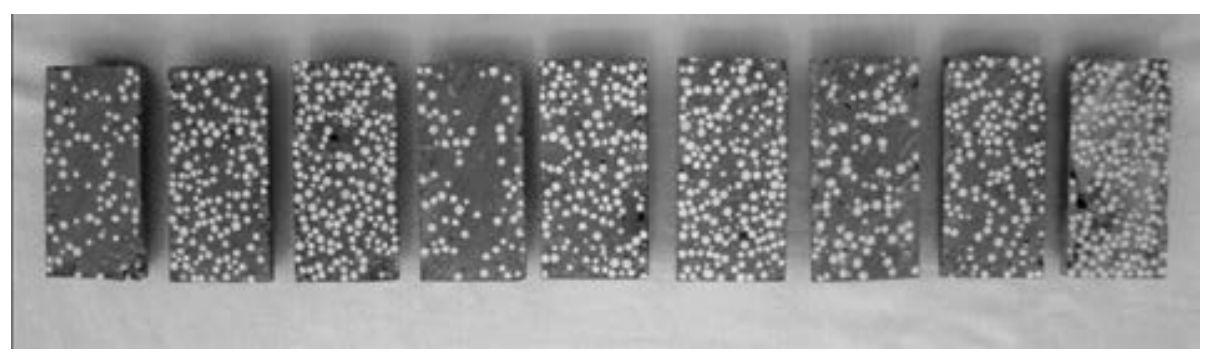

Fig. (4). Longitudinal section of specimens of all conditions studied.

Table 2 shows the results of analysis of variance (ANOVA) for the averages of the variables investigated. Factors related to $P$ value less than or equal to 0.05 (95\% confidence) are considered significant. The main effect of a factor is interpreted individually only if there is no evidence that the factor does not interact with other factors. When one or more interaction effects of higher order are significant factors that interact are discussed together [18]. The $P$ values, underlined in Table 2 correspond to the significant factors analyzed in this work. The R2 value displayed in ANOVA measures the variability present in the equation of regression; the closer to 1 (or 100\%) the better the data fit by the equation. The values of the volumetric density of the composites ranged from 1210 to $1640 \mathrm{~kg} / \mathrm{m}^{3}$. The $P$ value (0.00) 
outlined in Table 2 indicates that the effect is significant due to the fraction of polystyrene. On the other hand the $P$ value for the sand fraction $(0.476)$ is greater than 0.05 , indicating that this factor does not influence volumetric density. The adjusted R2 value was $99.05 \%$, indicating that the quality of the model fit was satisfactory. Fig. (5) shows the main factor effect chart of fraction of Styrofoam for the response variable volumetric density. As can be seen in Fig. (5) the polystyrene fraction directly affects the average value of the volumetric density with a mean percent variation of up to $32.7 \%$, that is, the larger the fraction of EPS the smaller the density of the composite due to the low density of Styrofoam $\left(300 \mathrm{~kg} / \mathrm{m}^{3}\right)$.

Table 2. Analysis of variance (ANOVA).

\begin{tabular}{|c|c|c|c|c|c|c|}
\hline & \multicolumn{3}{|c|}{ ANOVA } & \multicolumn{3}{c|}{ P - VALUE $\leq \mathbf{0 . 0 5}$} \\
\hline \multirow{3}{*}{ Main Factors } & Experimental Factors & Volumetric density & Bulk density & Apparent porosity & Compressive strength & $\begin{array}{c}\text { Dynamic modulus of } \\
\text { elasticity }\end{array}$ \\
& Sand fraction & 0.476 & $\underline{0.021}$ & $\underline{0.014}$ & 0.049 & $\underline{0.007}$ \\
\cline { 2 - 7 } & Polystyrene fraction & $\underline{0.000}$ & $\underline{0.000}$ & $\underline{0.000}$ & 0.000 & $\underline{0.000}$ \\
\hline $\begin{array}{c}\text { Factors } \\
\text { Interaction }\end{array}$ & $\begin{array}{c}\text { Sandfraction and Polystyrene } \\
\text { fraction }\end{array}$ & 0.253 & 0.304 & 0.085 & $\underline{0.028}$ & 0.080 \\
\cline { 2 - 7 } & $\mathrm{R}^{2}$ & $99.05 \%$ & $99.16 \%$ & $90.32 \%$ & $98.79 \%$ & $99.04 \%$ \\
\hline
\end{tabular}

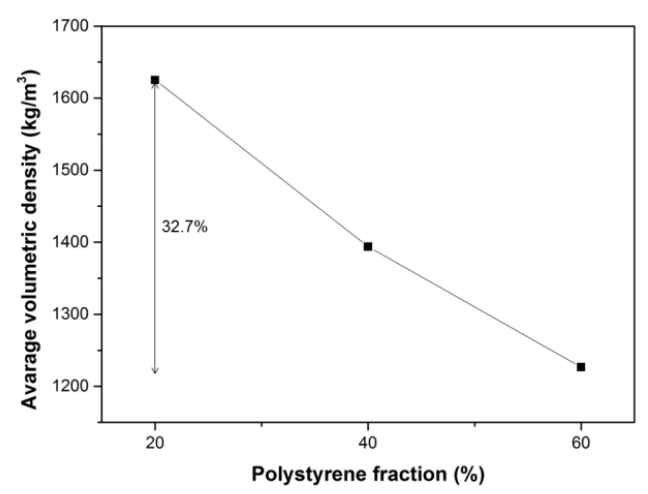

Fig. (5). Effect of polystyrene fraction on the average volumetric density of the composites.

The values of bulk density ranged between 1290 and $1800 \mathrm{~kg} / \mathrm{m}^{3}$, corresponding to a small average percent variation of $3.3 \%$. The main factors, sand fraction $(0.021)$ and polystyrene fraction $(0.000)$, are considered significant, showing $P$ value less than 0.05 . The R2 value set of $99.16 \%$ indicates the satisfactory adjustment of the model adopted for the results of the bulk density. Fig. (6) shows the effect of sand fraction on the response of the variable bulk density. Increasing density with increasing amount of sand was expected, since the bulk density of the sand particles is superior to the other constituents, increasing the density of composites. However, the increase of about $3.3 \%$ observed is relatively small due to the similar density of sand and Portland cement.

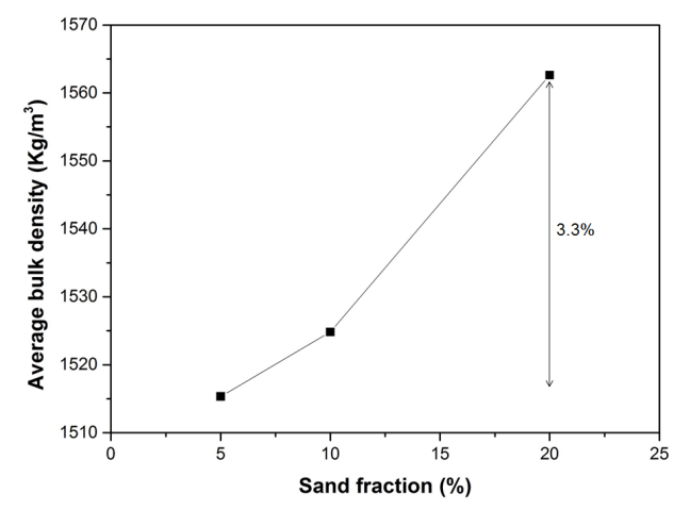

Fig. (6). Effect of sand fraction on the average bulk density of the composites. 
Fig. (7) shows the main factor effect chart fraction of Styrofoam for the response variable bulk density. Styrofoam contributes to the decrease in bulk density, as its bulk density is very low. An average percentage change of $36 \%$ is observed between 20 and $60 \%$ of Styrofoam additions. The influence of EPS on the density of the composite material is much more accentuated compared to the influence of sand, because of the much higher density difference between expanded polystyrene and Portland cement.

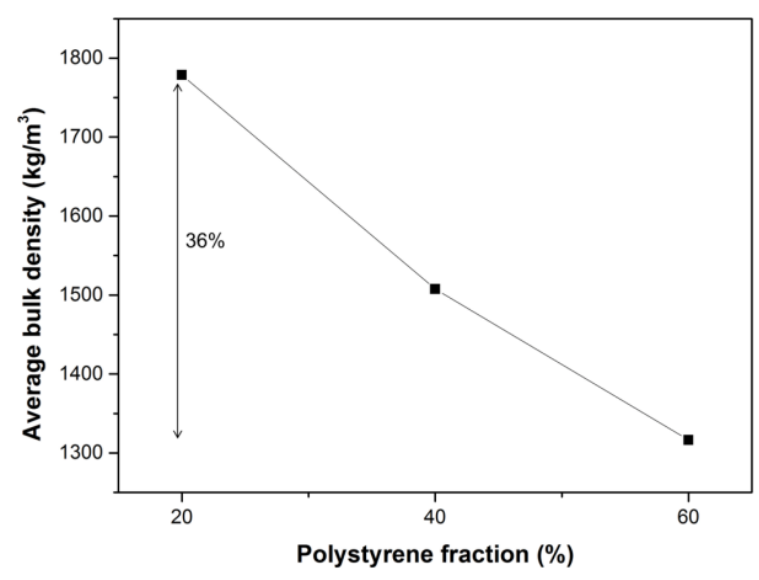

Fig. (7). Effect of polystyrene fraction on the average bulk density of the composites.

The apparent porosity values ranged from 8.93 to $11.68 \%$. The $P$ values for the main factors, sand $(0.014)$ and polystyrene fraction (0.000) show that each of them directly affects the response variable. The R 2 value set of $90.32 \%$ indicates the satisfactory adjustment of the model adopted for the apparent porosity results.

Fig. (8) shows the effect of the sand fraction on the response of the variable apparent porosity. It can be seen that the addition of sand particles promotes the reduction of apparent porosity in the composite for a fraction of up to $10 \%$ by mass. This behavior is attributed to a higher packing factor. However further addition of sand increased the apparent porosity.

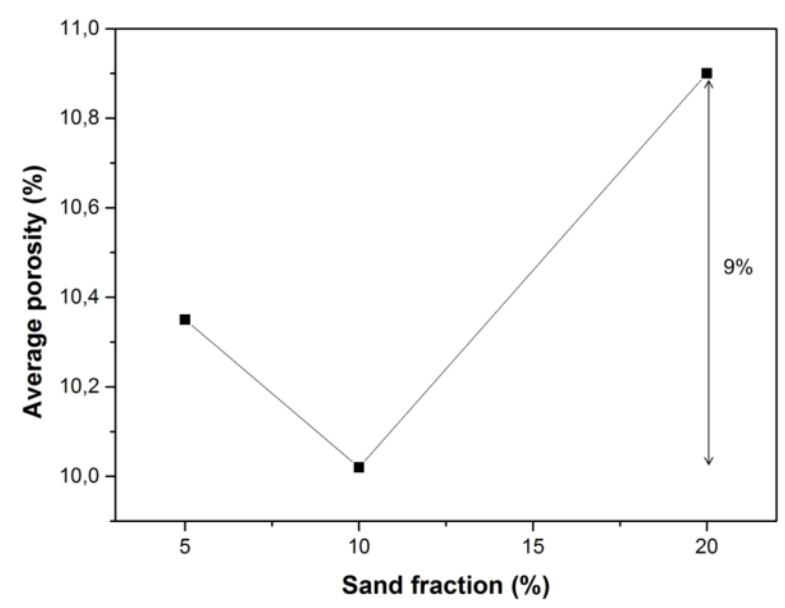

Fig. (8). Effect of sand fraction on the average apparent porosity of the composites.

Fig. (9) shows the main factor effect of the polystyrene fraction on the response variable apparent porosity. An average percentage change of $18.8 \%$ between fractions 20 and $60 \%$ Styrofoam can be observed. The increase in the percentage of polystyrene particles implies in the volume reduction of the cement matrix, which is responsible for the decreasing apparent porosity of the material. 


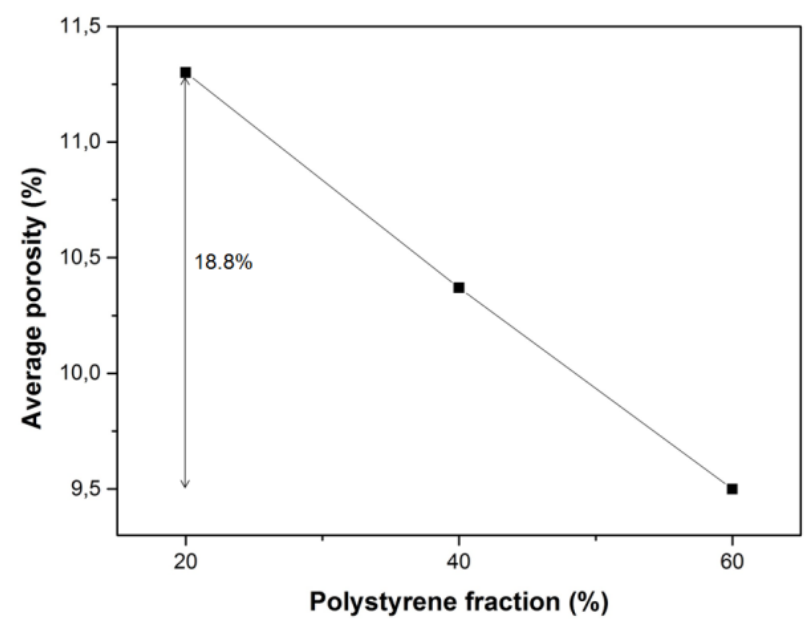

Fig. (9). Effect of polystyrene fraction on the average apparent porosity of the composites.

The composite compressive strength values ranged from 7.37 to $18.71 \mathrm{MPa}$. The second order interaction of "sand fraction and Styrofoam fraction" was significant, displaying a $P$ value of 0.028 (see Table 2). The adjusted R2 value of 98.79\% indicates that the model is properly adjusted to the results of compressive strength. Fig. (10) shows the effect of the interaction of the factors "sand fraction and polystyrene fraction" on compressive strength. It can be seen that although the interaction of two factors are significant the fraction of polystyrene causes a greater variation in compressive strength, revealing a percentage of approximately $121 \%$ difference between fractions 20 and $60 \%$, since their mechanical properties are insignificant when compared to the cement properties. Note that the effect of the addition of sand on the resistance varies depending on the level of added polystyrene, which can be attributed to the particle packing factor.

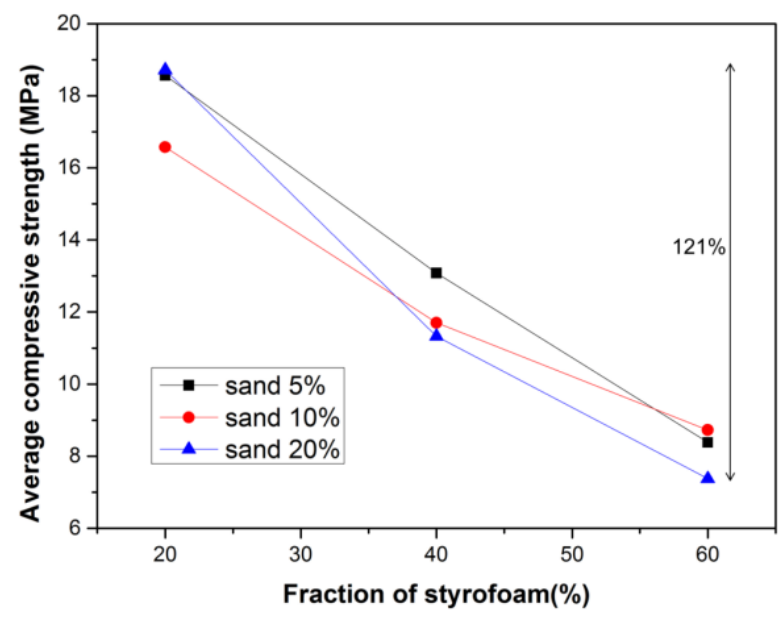

Fig. (10). Interaction effect of sand fraction and fraction of styrofoam on the average compressive strength.

The values of the dynamic modulus of elasticity ranged from 26.06 to $37.31 \mathrm{GPa}$. The $P$ values for major factors sand fraction (0.007) and polystyrene fraction (0.000), show that each of them affects directly the variable response. The R2 value set of $99.04 \%$ indicates a satisfactory fit of the model adopted the results of dynamic modulus of elasticity.

Fig. (11) shows the effect of the sand fraction of the main outcome variable for the dynamic modulus of elasticity. The addition of sand particles promotes an increase of $4.4 \%$ of the dynamic modulus of elasticity which can be attributed to the higher stiffness of the sand particles (silica).

Fig. (12) shows the effect of the polystyrene fraction on the response of the dynamic modulus of elasticity. As the volume fraction of the polystyrene increases, there is a $35 \%$ percent reduction in the value of the dynamic modulus of 
elasticity due to the very low polystyrene modulus. Importantly, the method of measuring the modulus of elasticity by the resonance frequency was able to detect this type of aggregate and its fractions, being a suitable technique for the characterization of this type of composite.

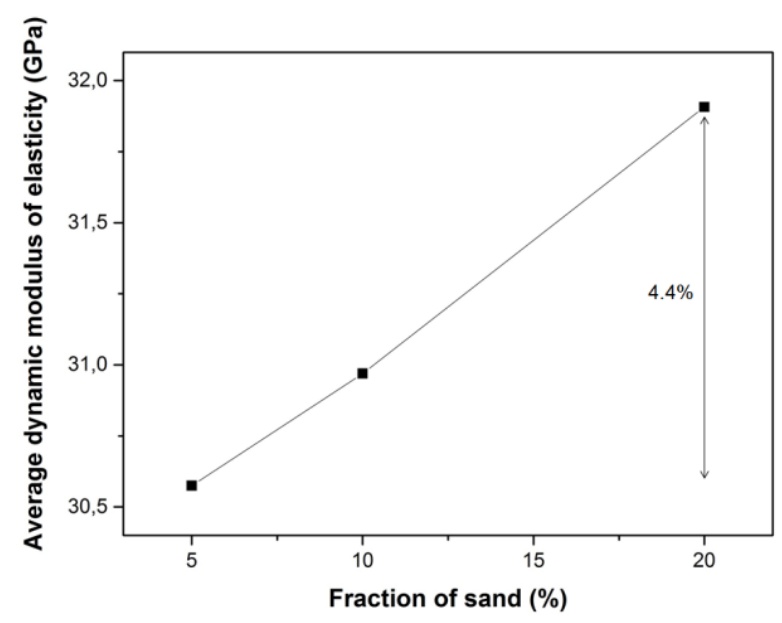

Fig. (11). Effect of fraction of sand on the average dynamic modulus of elasticity of composite.

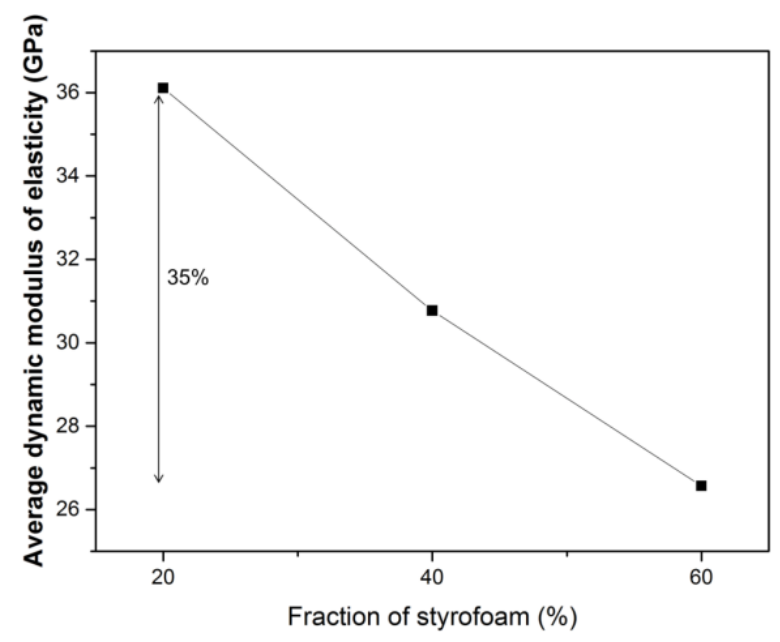

Fig. (12). Effect of fraction of styrofoam on the average dynamic modulus of elasticity of composite.

\subsection{Finite Element Analysis}

In general, the failure modes in particle-reinforced composites has been related to the basic problem of a matrix crack interacting with second phase particles [20]. The mechanical stability of a particle reinforced matrix is of great importance in terms of their engineering applications. Therefore, it is necessary to analyze of effect of particle size and volume fraction on the generated stresses in the polystyrene-cement composite. Fig. (13) shows the Von Mises stress values for hole diameters of 3.5 and $5 \mathrm{~mm}$ with different volume fractions. A larger particle diameter ( $5 \mathrm{~mm})$ provided an increase of the Von Mises stress in the composite. This behavior confirmed the presence of a particle size effect on the polystyrene-cement strength. This effect is intensified when the composites are manufactured with a higher volume of Styrofoam particles. Miled et al. [21] reported that the lower the inclusion size, the greater the concrete normalized compressive strength. On the other hand, the authors concluded that the EPS concrete failure mode depends greatly on its porosity. As shown in Fig. (13), the maximum stress was observed at the particle surface. 


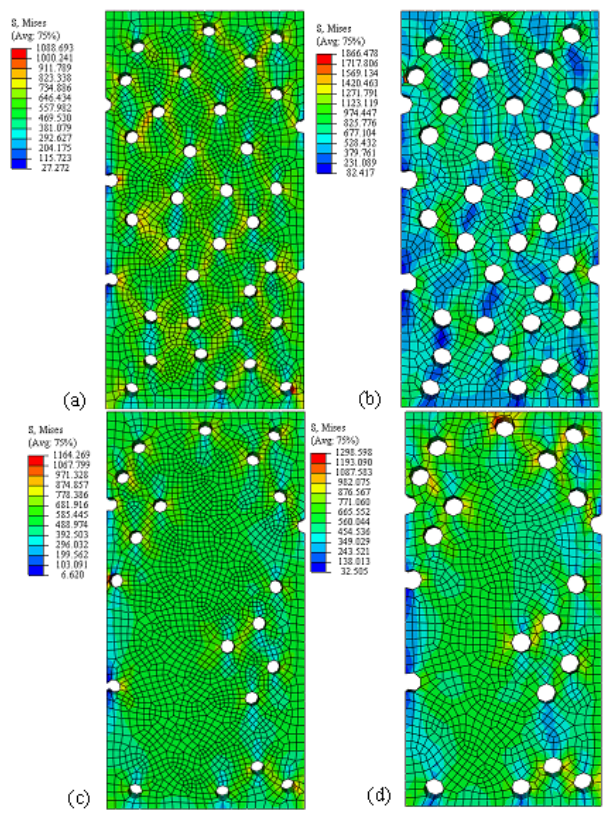

Fig. (13). Von Mises stress for model A (a), model B (c), model C (b) and model D (d).

Fig. (14) exhibits the normal residual stresses ( $\sigma x x)$ for different hole diameters and volume fractions. As observed for the Von Mises stress, the changes in normal stress were provided by an increase in the diameter particle. The maximum stress was adjacent to the interface particle-matrix. It was noted that the normal residual stresses tended to zero when the distance from the interface was increased. Besides, a lower amount of particles resulted in a reduction of the normal stress $(\sigma \mathrm{xx})$.

The changes in the normal residual stresses (бyy) are illustrated in Fig. (15) for different particle diameters and volume fractions. With increasing particle diameter significant variations in the stress level occur. A larger particle size provided an increase of the normal stress (бyy). The variations in residual stress at the interface are the same as shown in Fig. (14). As shown in Figs. (14 and 15), the normal stresses are concentrated at the particle-matrix interface. The same results were reported by Bouafia [19].

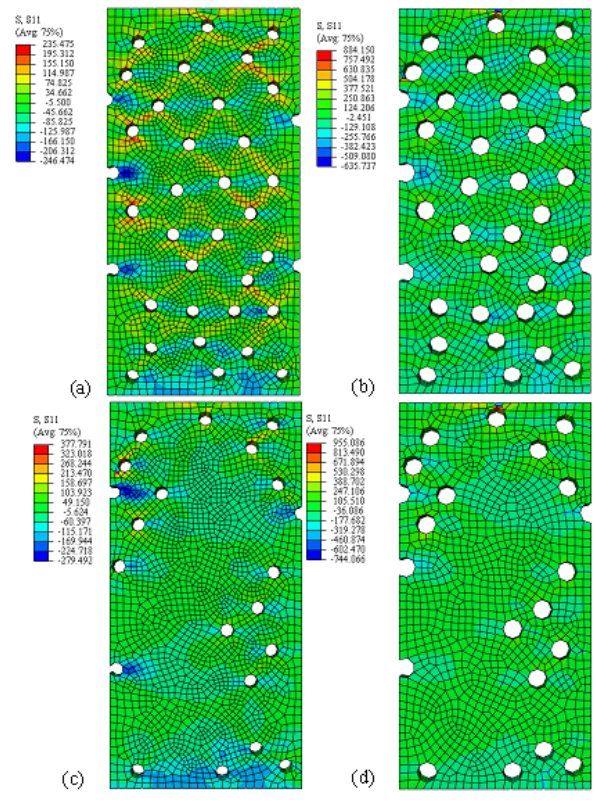

Fig. (14). Normal stress ( $\sigma \mathrm{xx})$ for model A (a), model B (c), model C (b) and model D (d). 


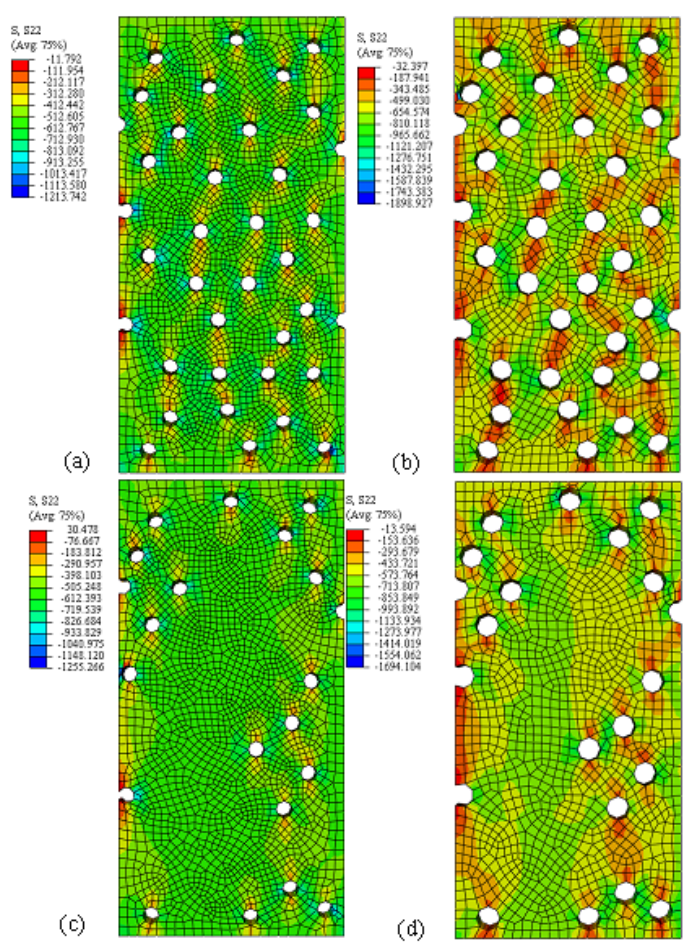

Fig. (15). Normal stress ( $\sigma y y)$ for model A (a), model B (c), model C (b) and model D (d).

\section{CONCLUSION}

From the present results, it can be concluded that:

-The amount of sand exercises little influence on the properties of the prepared composites even in cases where a significant interaction was observed in the results of bulk density, apparent porosity, and modulus of elasticity. Variations in these properties were observed below $10 \%$.

-However the quantity of added Styrofoam significantly affects any properties of the prepared composites studied, achieving a $121 \%$ variation in the average value of the compressive strength;

- The composite of lowest density $\left(1210 \mathrm{~kg} / \mathrm{m}^{3}\right)$ was prepared with $60 \%$ polystyrene and obtained a compressive strength of $8.38 \mathrm{MPa}$;

-Based on the finite element analysis the amount of the stress in the composite increases with the increasing particle diameter;

- The method of resonance frequency was suitable for the characterization of cementitious composites with polystyrene particles, being able to detect not only the aggregate particle type, as well as the percentage added. It also follows that the polystyrene incorporation in larger amounts may further reduce the density while maintaining a sufficient strength for non-structural applications such as coating panel, curtain wall and flooring.

\section{CONFLICT OF INTEREST}

The authors confirm that this article content has no conflict of interest.

\section{ACKNOWLEDGEMENTS}

Declared none.

\section{REFERENCES}

[1] A. Short, and W. Kinniburgh, Lightweight Concrete, $3^{\text {rd }}$ ed. DA Information Service: Australia, 1978.

[2] V. Sussman, "Lightweight plastic aggregate concrete", J. ACI, pp. 321-323, 1975.

[3] D.J. Cook, Expanded Polystyrene Concrete, Concrete Technology and Design": (1) New Concrete Materials, Surrey University Press: London, UK, 1983, pp. 41-69. 
[4] A. Godwin, "Versatile concrete blocks for the third world", J. Indian Concr., pp. 240-241, 1982.

[5] A. N. Hanna, "Properties of Expanded Polystyrene Concrete and Applications for Pavement Sub-Bases", Report RD055.01P, Portland Cement Association, 1978.

[6] C. Bagon, and S. Frondistou-Yannas, "Marine fl concrete made with polystyrene expanded beads", Mag. Concr. Res., vol. 28, pp. 225-229, 1976. [http://dx.doi.org/10.1680/macr.1976.28.97.225]

[7] S.H. Perry, P.H. Bischaff, and K. Yamura, "Mix details and material behavior of polystyrene aggregate concrete", Mag. Concr. Res., vol. 43, pp. 71-76, 1991.

[http://dx.doi.org/10.1680/macr.1991.43.154.71]

[8] G.C. Hoff, "New applications for low density concretes, Lightweight concrete", ACI, vol. 29, pp. 181-220, 1971.

[9] P.H. Bischoff, K. Yamura, and S.H. Perry, "Polystyrene aggregate concrete subjected to hard impact", Proc. Inst. Civil Eng., vol. 89, no. 2, pp. 225-239, 1989.

[10] D. J. Cook, "Expanded polystyrene beads as lightweight aggregate for concrete", Precast Concr., vol. 4, pp. 691-693, 1973. [http://dx.doi.org/10.1016/0958-9465(94)90039-6]

[11] R.S. Ravindrarajah, and A.J. Tuck, "Properties of hardened concrete containing treated expanded polystyrene beads", Cem. Concr. Compos., vol. 16, pp. 273-277, 1994.

[http://dx.doi.org/10.1016/0958-9465(94)90039-6]

[12] K. Babu, and D.S. Babu, "Behaviour of lightweight expanded polystyrene concrete containing silica fume", Cem. Concr. Res., vol. 33, pp. 755-762, 2003. [http://dx.doi.org/10.1016/S0008-8846(02)01055-4]

[13] M.H. Zhang, and O.E. Gjorv, "Mechanical properties of high strength lightweight concrete", ACI Mater. J., vol. 88, no. 3, pp. 240-247, 1991.

[14] W.C. Tang, Y. Lo, and A. Nadeem, "Mechanical and drying shrinkage properties of structural graded polystyrene aggregate concrete", Cem. Concr. Compos., vol. 30, pp. 403-409, 2008.

[http://dx.doi.org/10.1016/j.cemconcomp.2008.01.002]

[15] K. Babu, and D.S. Babu, "Performance of flash concretes containing lightweight EPS aggregates", Cem. Concr. Compos., vol. 26, pp. 605-611, 2004. [http://dx.doi.org/10.1016/S0958-9465(03)00034-9]

[16] British Standards Institute, Ceramic Tiles: Determination of Water Absorption, Apparent Porosity, Apparent Relative Density and Bulk Density, BSI Standards: UK, 1997.

[17] "Standard Test Method for Fundamental Transverse, Longitudinal, and Torsional Frequencies", C215, ASTM International: US, 2008.

[18] M.C. Werkema, and S. Aguiar, Planejamento e Análise de Experimentos: Como Identifi e Avaliar as Principais Variáveis infl Emum Processo, Fundação Christiano Ottoni, Escola de Engenharia da UFMG: Belo Horizonte, 2013.

[19] F. Bouafia, B. Serier, B. Abbes, and B. Bouiadjra, "Finite element analysis of the thermal residual stresses of SiC particle reinforced aluminum composite", Comput. Mater. Sci., vol. 54, pp. 195-203, 2012. [http://dx.doi.org/10.1016/j.commatsci.2011.10.030]

[20] W. Wang, K. Sadeghipour, and G. Baran, "Finite element analysis of the effect of an interphase on toughening of a particle reinforced polymer composite", Compos., Part A Appl. Sci. Manuf., vol. 39, no. 6, pp. 956-964, 2008. [http://dx.doi.org/10.1016/j.compositesa.2008.03.016] [PMID: 19492012]

[21] K. Miled, K. Sab, and R.L. Roy, "Particle size effect on EPS lightweight concrete compressive strength: Experimental investigation and modelling", Mech. Mater., vol. 39, pp. 222-240, 2007. [http://dx.doi.org/10.1016/j.mechmat.2006.05.008]

(C) Strecker et al.; Licensee Bentham Open.

This is an open access article licensed under the terms of the Creative Commons Attribution-Non-Commercial 4.0 International Public License (CC BY-NC 4.0) (https://creativecommons.org/licenses/by-nc/4.0/legalcode), which permits unrestricted, non-commercial use, distribution and reproduction in any medium, provided the work is properly cited. 